\title{
Guidance Law Design Using Intelligent Non-Linear Controller
}

\author{
Y. Z. Elhalwagy*
}

\begin{abstract}
A sliding mode control algorithm combined with a fuzzy control scheme is developed for the trajectory control of a command guidance system. The acceleration command input is obtained. The proposed controller is used to compensate for the influence of unmodeled dynamics and to alleviate chattering. Simulation results show that the proposed controller gives good system performance in the face of system parameters variation and external disturbances. Moreover, the simulation results show the effectiveness of the proposed missile guidance law against different engagement scenarios.
\end{abstract}

Keywords: Sliding mode control, fuzzy logic, missile guidance.

\section{Introduction}

The design of guidance laws and/or controllers for guided missile is challenging because of difficulties in accurately modelling the inherently non-linear dynamics of guided missiles in uncertain environment with persistent unmodelled disturbances.

Extensive research efforts have been made over the years to design or improve flight guidance and control systems. With the phenomenal growth of highly manoeuvrable targets, research on improved guidance laws is continuing [1-6]. In recent years, many authors have addressed the importance of the command-to-line-of-sight (CLOS) guidance law due to the recent advances in beam-pointing technology [7-12].

The sliding mode control (SMC) law is a substantial case from the wider class commonly referred to as variable structure control (VSC). An advantage of these methods of control is their robustness to parameter perturbations and bounded external disturbances. The robustness is attributed to the discontinuous term in the control input. However, this discontinuous term also causes an undesirable effect called chattering. Recent applications of SMC to design missile guidance law [13-15] resulted in a series of very promising algorithms to improve stability and robustness of the guidance loop.

For example, Brierly and Longchamp [13] have applied a sliding mode control to a nonlinear system representing an air-to-air missile target engagement scenario. Babu, Sarma, and Swamy [15] proposed a proportional navigation (PN) guidance law with an additive switched bias term for short range homing missile by invoking SMC theory. So far all the applications of SMC are restricted to the homing guidance law design which is most probably a PN-based guidance law.

\footnotetext{
* Egyptian Armed Forces
} 
Due to the similarity between fuzzy logic control (FLC) [16] and sliding mode control (SMC) [17], there is growing interest to combine both these techniques to design what is called fuzzy sliding mode controller (FSMC) [18]. Basically, the most attractive feature of FLC is that expert knowledge can be easy incorporated into the design process. While the stability of FLC is still questionable, the stability of SMC is inherent. Thus, the strengths of a FSMC coincide with the missile guidance law design requirements.

This work addresses an application of sliding-mode control to design a robust missile command guidance law. To alleviate chattering, a hybrid sliding mode controller and fuzzy logic controller is proposed. FSMC has an advantage that the stability can be proved easily in terms of SMC theory. Furthermore, the rules of the proposed FSMC are independent of the number of system state variables because the input of the suggested controller is fuzzy quantity sliding surface value. Hence the rules of the proposed FSMC can be reduced.

The paper is organized as follows. In section 2, a three-dimensional missile-target interception process is presented. The nonlinear differential equations that describe the missile dynamics in the space are given to show the nonlinearities in the system kinematics and dynamics. Section 3 is devoted to a brief description of SMC theory and the derivation of the missile command guidance law. In sections 4 an investigations of designing missile guidance laws based on the FSMC theory to improve robustness are presented. Evaluations of the threedimensional missile-target engagement scenarios are given in section 5. Finally, this paper ends with the conclusions and recommendations for further research.

\section{Problem Formulation}

The three-dimensional CLOS guidance problem can be formulated as a tracking error problem for a time-varying nonlinear system. The three-dimensional missile-target interception geometry is shown in Fig. 1. The origin of the inertial frame is located at the ground tracker, while that of the missile body frame is fixed at the missile's centre of mass. The motion of the missile in the inertial frame can be represented by [7]:

$$
\begin{aligned}
& \ddot{x}_{\mathrm{m}}=\mathrm{a}_{\mathrm{x}} \mathrm{c} \theta_{\mathrm{m}} \mathrm{c} \psi_{\mathrm{m}}-\mathrm{a}_{\mathrm{yc}}\left(\mathrm{s} \phi_{\mathrm{mc}} \mathrm{s} \theta_{\mathrm{m}} \mathrm{c} \psi_{\mathrm{m}}+\mathrm{c} \phi_{\mathrm{mc}} \mathrm{s} \psi_{\mathrm{m}}\right)-\mathrm{a}_{\mathrm{zc}}\left(\mathrm{c} \phi_{\mathrm{mc}} \mathrm{s} \theta_{\mathrm{m}} \mathrm{c} \psi_{\mathrm{m}}-\mathrm{s} \phi_{\mathrm{mc}} \mathrm{s} \psi_{\mathrm{m}}\right) \\
& \ddot{\mathrm{y}}_{\mathrm{m}}=\mathrm{a}_{\mathrm{x}} \mathrm{c} \theta_{\mathrm{m}} \mathrm{s} \psi_{\mathrm{m}}-\mathrm{a}_{\mathrm{yc}}\left(\mathrm{s} \phi_{\mathrm{mc}} \mathrm{s} \theta_{\mathrm{m}} \mathrm{s} \psi_{\mathrm{m}}-\mathrm{c} \phi_{\mathrm{mc}} \mathrm{s} \psi_{\mathrm{m}}\right)-\mathrm{a}_{\mathrm{zc}}\left(\mathrm{c} \phi_{\mathrm{mc}} \mathrm{s} \theta_{\mathrm{m}} \mathrm{s} \psi_{\mathrm{m}}+\mathrm{s} \phi_{\mathrm{mc}} \mathrm{c} \psi_{\mathrm{m}}\right) \\
& \ddot{\mathrm{z}}_{\mathrm{m}}=\mathrm{a}_{\mathrm{x}} \mathrm{s} \theta_{\mathrm{m}}+\mathrm{a}_{\mathrm{yc}} \mathrm{s} \phi_{\mathrm{mc}} \mathrm{c} \theta_{\mathrm{m}}+\mathrm{a}_{\mathrm{zc}} \mathrm{c} \phi_{\mathrm{mc}} \mathrm{c} \theta_{\mathrm{m}}-\mathrm{g} \\
& \dot{\psi}_{\mathrm{m}}=\mathrm{a}_{\mathrm{yc}} \mathrm{c} \phi_{\mathrm{mc}} /\left(\mathrm{v}_{\mathrm{m}} \mathrm{c} \theta_{\mathrm{m}}\right)-\mathrm{a}_{\mathrm{zc}} \mathrm{s} \phi_{\mathrm{mc}} /\left(\mathrm{v}_{\mathrm{m}} \mathrm{c} \theta_{\mathrm{m}}\right) \\
& \dot{\theta}_{\mathrm{m}}=\mathrm{a}_{\mathrm{yc}} \mathrm{s} \phi_{\mathrm{mc}} / \mathrm{v}_{\mathrm{m}}+\mathrm{a}_{\mathrm{zc}} \mathrm{c} \phi_{\mathrm{mc}} / \mathrm{v}_{\mathrm{m}}-\mathrm{gc} \theta_{\mathrm{m}} / \mathrm{v}_{\mathrm{m}}
\end{aligned}
$$

where $\theta_{\mathrm{m}}, \psi_{\mathrm{m}}$, and $\phi_{\mathrm{mc}}$ are missile pitch and yaw angles, and roll angle command respectively, and $\mathrm{x}_{\mathrm{m}}, \mathrm{y}_{\mathrm{m}}$, and $\mathrm{z}_{\mathrm{m}}$ are the missile position in the inertial frame. The notation $\mathrm{s} \psi_{\mathrm{m}}, \mathrm{c} \psi_{\mathrm{m}}$, etc. are the $\sin \psi_{\mathrm{m}}$ and $\cos \psi_{\mathrm{m}}$, etc. $\mathrm{v}_{\mathrm{m}}$ denotes the missile velocity given by

$$
\mathrm{v}_{\mathrm{m}} \stackrel{\Delta}{=}\left(\dot{\mathrm{x}}_{\mathrm{m}}^{2}+\dot{\mathrm{y}}_{\mathrm{m}}^{2}+\dot{\mathrm{z}}_{\mathrm{m}}^{2}\right)^{1 / 2}
$$

$\mathrm{a}_{\mathrm{zc}}$ and $\mathrm{a}_{\mathrm{yc}}$, represent the pitch and yaw command of the missile respectively, while $\mathrm{a}_{\mathrm{x}}$ represents the axial acceleration of the missile given by

$$
\mathrm{a}_{\mathrm{x}} \stackrel{\Delta}{=}(\mathrm{T}-\mathrm{D}) / \text { mass }
$$


where $\mathrm{T}, \mathrm{D}$, and mass represent the thrust force, drag force, and mass of the missile respectively.

The system in (1) could be rewritten as

$$
\begin{aligned}
& {\left[\begin{array}{l}
\ddot{x}_{\mathrm{m}} \\
\ddot{y}_{\mathrm{m}} \\
\ddot{z}_{\mathrm{m}}
\end{array}\right]=\left[\begin{array}{ccc}
\mathrm{c} \theta_{\mathrm{m}} \mathrm{c} \psi_{\mathrm{m}} & -\left(\mathrm{s} \phi_{\mathrm{mc}} \mathrm{s} \theta_{\mathrm{m}} \mathrm{c} \psi_{\mathrm{m}}+\mathrm{c} \phi_{\mathrm{mc}} \mathrm{s} \psi_{\mathrm{m}}\right) & -\left(\mathrm{c} \phi_{\mathrm{mc}} \mathrm{s} \theta_{\mathrm{m}} \mathrm{c} \psi_{\mathrm{m}}-\mathrm{s} \phi_{\mathrm{mc}} \mathrm{s} \psi_{\mathrm{m}}\right) \\
\mathrm{c} \theta_{\mathrm{m}} \mathrm{s} \psi_{\mathrm{m}} & -\left(\mathrm{s} \phi_{\mathrm{mc}} \mathrm{s} \theta_{\mathrm{m}} \mathrm{s} \psi_{\mathrm{m}}-\mathrm{c} \phi_{\mathrm{mc}} \mathrm{s} \psi_{\mathrm{m}}\right) & -\left(\mathrm{c} \phi_{\mathrm{mc}} \mathrm{s} \theta_{\mathrm{m}} \mathrm{s} \psi_{\mathrm{m}}+\mathrm{s} \phi_{\mathrm{mc}} \mathrm{c} \psi_{\mathrm{m}}\right) \\
\mathrm{s} \theta_{\mathrm{m}} & \mathrm{s} \phi_{\mathrm{mc}} \mathrm{c} \theta_{\mathrm{m}} & \mathrm{c} \phi_{\mathrm{mc}} \mathrm{c} \theta_{\mathrm{m}}
\end{array}\right]\left[\begin{array}{c}
\mathrm{a}_{\mathrm{x}} \\
\mathrm{a}_{\mathrm{yc}} \\
\mathrm{a}_{\mathrm{zc}}
\end{array}\right]-\left[\begin{array}{l}
0 \\
0 \\
\mathrm{~g}
\end{array}\right]} \\
& \stackrel{\Delta}{=} \mathrm{T}_{\mathrm{IM}}\left[\begin{array}{c}
\mathrm{a}_{\mathrm{x}} \\
\mathrm{a}_{\mathrm{yc}} \\
\mathrm{a}_{\mathrm{zc}}
\end{array}\right]-\left[\begin{array}{l}
0 \\
0 \\
\mathrm{~g}
\end{array}\right]
\end{aligned}
$$

where $\mathrm{g}$ is the gravity acceleration. The CLOS guidance involves guiding the missile onto the LOS to target. Therefore a reasonable choice of tracking error may be

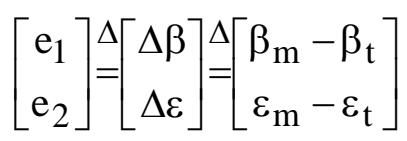

where $\varepsilon_{\mathrm{m}}, \beta_{\mathrm{m}}, \varepsilon_{\mathrm{t}}, \beta_{\mathrm{t}}$ are the missile and target line of sight (LOS) angles in pitch and yaw planes respectively. An alternative approach for the choice of the tracking error is

$$
\left[\begin{array}{l}
\mathrm{e}_{1} \\
\mathrm{e}_{2}
\end{array}\right]=\left[\begin{array}{cc}
\left(\mathrm{x}_{\mathrm{m}}^{2}+\mathrm{y}_{\mathrm{m}}^{2}\right)^{1 / 2} & 0 \\
0 & \mathrm{R}_{\mathrm{m}}
\end{array}\right]\left[\begin{array}{l}
\beta_{\mathrm{m}}-\beta_{\mathrm{t}} \\
\varepsilon_{\mathrm{m}}-\varepsilon_{\mathrm{t}}
\end{array}\right]
$$

where $\mathrm{R}_{\mathrm{m}}$ is the missile slant range. Even in small tracking error, however, the selections in (5) and (6) could cause large miss distance as the missile flies farther from the launching point. To overcome this problem a third choice of the tracking error as defined in [7] could be as follows:

$$
\begin{gathered}
{\left[\begin{array}{l}
\mathrm{e}_{1} \\
\mathrm{e}_{2}
\end{array}\right] \stackrel{\Delta}{=}\left[\begin{array}{ccc}
-\mathrm{s} \beta_{\mathrm{t}} & \mathrm{c} \beta_{\mathrm{t}} & 0 \\
-\mathrm{s} \varepsilon_{\mathrm{t}} \mathrm{c} \beta_{\mathrm{t}} & -\mathrm{s} \varepsilon_{\mathrm{t}} \mathrm{s} \beta_{\mathrm{t}} & \mathrm{c} \varepsilon_{\mathrm{t}}
\end{array}\right]\left[\begin{array}{l}
\mathrm{x}_{\mathrm{m}} \\
\mathrm{y}_{\mathrm{m}} \\
\mathrm{z}_{\mathrm{m}}
\end{array}\right]} \\
\quad \stackrel{\Delta}{=} \mathrm{D}(\mathrm{t})\left[\begin{array}{c}
\mathrm{x}_{\mathrm{m}} \\
\mathrm{y}_{\mathrm{m}} \\
\mathrm{z}_{\mathrm{m}}
\end{array}\right]
\end{gathered}
$$

It is noticed that $\mathrm{D}(\mathrm{t})$ and $\mathrm{T}_{\mathrm{IM}}$ matrices are right invertible with its right inverse equal to the transposition. In another words,

$$
\mathrm{D}(\mathrm{t}) \mathrm{D}^{\mathrm{T}}(\mathrm{t})=\mathrm{I}_{2 \times 2}, \mathrm{~T}_{\mathrm{IM}}(\mathrm{t}) \mathrm{T}_{\mathrm{IM}}^{\mathrm{T}}(\mathrm{t})=\mathrm{I}_{3 \times 3} \quad \forall \mathrm{t}>0
$$

The objective of the CLOS guidance law design is to find the body acceleration commands $\mathrm{a}_{\mathrm{yc}}$ and $\mathrm{a}_{\mathrm{zc}}$ of the missile such that the tracking error vector asymptotically approach 0 .

In this paper an application of sliding-mode control to design a more robust stable missile command guidance law will be presented in the following sections. 


\section{Sliding Mode Command Guidance}

\subsection{Sliding mode control}

Consider the problem of designing a sliding mode controller for the nth-order system as the following

$$
\dot{\mathrm{X}}(\mathrm{t})=\mathrm{A}(\mathrm{t}, \mathrm{x}) \mathrm{X}(\mathrm{t})+\mathrm{B}(\mathrm{t}, \mathrm{x}) \mathrm{u}(\mathrm{t})
$$

where $\mathrm{X}=\left[\mathrm{x}_{1}, \ldots, \mathrm{x}_{\mathrm{n}}\right]^{\mathrm{T}}$ is the state vector, $\mathrm{A}$ is an $(\mathrm{n} \times \mathrm{n})$ matrix, $\mathrm{B}$ is an $(\mathrm{n} \times \mathrm{r})$ matrix, and $\mathrm{u}$ is an $(\mathrm{r} \times 1)$ control input matrix.

The error tracking control problem is to derive a control law $\mathrm{u}$ such that the state $\mathrm{X}$ traces the desired trajectory $\mathrm{X}_{\mathrm{d}}=\left[\mathrm{x}_{1 \mathrm{~d}}, \ldots, \mathrm{x}_{\mathrm{nd}}\right]^{\mathrm{T}}$.

Let the tracking error vector e defined as

$$
\mathrm{e}=\mathrm{x}-\mathrm{x}_{\mathrm{d}} \text {. }
$$

To apply the sliding mode control theory, let the time-varying sliding surface $\mathrm{s}(\mathrm{x}, \mathrm{t})$ be defined in the state-space $\mathrm{R}^{\mathrm{n}}$ by $\mathrm{s}(\mathrm{x}, \mathrm{t})=0$ where

$$
\mathrm{s}(\mathrm{x}, \mathrm{t})=\left(\frac{\mathrm{d}}{\mathrm{dt}}+\lambda\right) \mathrm{e}=\dot{\mathrm{e}}+\lambda \mathrm{e}
$$

in which $\lambda$ is a positive diagonal constant matrix. It is obvious from (12) that keeping system states on the sliding surface $\mathrm{S}(\mathrm{t}) \forall \mathrm{t}>0$ will guaranty the tracking error vector asymptotically approach zero. The corresponding sliding condition [17] is

$$
\frac{1}{2} \frac{\mathrm{d}}{\mathrm{dt}} \mathrm{s}^{2} \leq-\eta \quad \mathrm{s} \neq 0, \eta>0
$$

Referring to Lyapunov stability method [17], the system in (9) is asymptotically stable to $\mathrm{S}(\mathrm{x}, \mathrm{t})=0$ for all the initial condition $\mathrm{x}\left(\mathrm{t}_{\mathrm{o}}\right) \in \Omega$, where $\Omega=\{\mathrm{x}: \mathrm{s}(\mathrm{x}, \mathrm{t}) \dot{\mathrm{s}}(\mathrm{x}, \mathrm{t})<0 \forall \mathrm{t}\}$, if $\mathrm{s}(\mathrm{x}) \dot{\mathrm{s}}(\mathrm{x})<0$ evaluated along a solution $\mathrm{x}$ for all $\mathrm{x} \in \Omega$.

Let $\hat{\mathrm{u}}$ be the equivalent control law that can be derived by setting $\dot{\mathrm{s}}(\mathrm{x}, \mathrm{t})=0$. Assume that the trajectories lie on the switching surface $s(x, t)=0$, then the derivative $\dot{s}(x, t)$ must be zero in order that the trajectories remain there and eventually tracking errors would be driven to zero. Thus, the general control structure that satisfies the stability condition of sliding motion, (12), can be given as

$$
\mathrm{u}=\hat{\mathrm{u}}-\mathrm{K} \operatorname{sign}[\mathrm{s}(\mathrm{x}, \mathrm{t})]
$$

where $\operatorname{sign}($.$) is the signum function and \mathrm{K}$ is a column vector of dimension $\mathrm{n}$ whose elements are $\mathrm{k}_{\mathrm{i}}>0$. The sliding condition can be satisfied as long as each $\mathrm{k}_{\mathrm{i}}$ is chosen large enough [17].

\subsection{The command guidance law derivation}

To apply SMC theory to the missile command guidance law design, a switching surface that represents the desired system dynamics is to be chosen. The following error matrix $s(x, t)$ defines the switching surface as the following 


$$
s(x, t)=\left[\begin{array}{c}
\left(d / d t+\lambda_{1}\right) e_{1} \\
\left(d / d t+\lambda_{2}\right) e_{2}
\end{array}\right]
$$

where error vector $\mathrm{e}_{\mathrm{i}}, \mathrm{i}=1,2$ is defined in $\mathrm{Eq}$ (15).

Let $\mathrm{X}(\mathrm{t})=\left(\mathrm{x}_{\mathrm{m}}, \mathrm{y}_{\mathrm{m}}, \mathrm{z}_{\mathrm{m}}, \dot{\mathrm{x}}_{\mathrm{m}}, \dot{\mathrm{y}}_{\mathrm{m}}, \dot{\mathrm{z}}_{\mathrm{m}}, \psi_{\mathrm{m}}, \theta_{\mathrm{m}}\right), \mathrm{u}(\mathrm{t})=\left(\mathrm{a}_{\mathrm{x}}, \mathrm{a}_{\mathrm{yc}}, \mathrm{a}_{\mathrm{zc}}\right)$, and $\mathrm{e}(\mathrm{t})=\left(\mathrm{e}_{1}, \mathrm{e}_{2}\right)$. Then we obtain the state space system as

$$
\begin{aligned}
& \dot{X}(t)=A(t, x) X(t)+B(t, x) u(t) \\
& e(t)=C(t) X(t)
\end{aligned}
$$

where

$$
\begin{aligned}
& A(x, t)=\left[\begin{array}{ccc}
0_{3 \times 3} & \mathrm{I}_{3 \times 3} & 0_{3 \times 2} \\
0_{5 \times 3} & 0_{5 \times 3} & 0_{5 \times 2}
\end{array}\right]_{8 \times 8}, \mathrm{~B}(\mathrm{x}, \mathrm{t})=\left[\begin{array}{c}
0_{3 \times 3} \\
\mathrm{~T}_{\mathrm{IM}} \\
\mathrm{F}_{2 \times 3}
\end{array}\right]_{8 \times 3} \\
& \mathrm{~F}=\left[\begin{array}{ccc}
0 & \mathrm{c} \phi_{\mathrm{mc}} /\left(\mathrm{v}_{\mathrm{m}} \mathrm{c} \theta_{\mathrm{m}}\right) & -\mathrm{s} \phi_{\mathrm{mc}} /\left(\mathrm{v}_{\mathrm{m}} \mathrm{c} \theta_{\mathrm{m}}\right) \\
0 & \mathrm{~s} \phi_{\mathrm{mc}} / \mathrm{v}_{\mathrm{m}} & \mathrm{c} \phi_{\mathrm{mc}} / \mathrm{v}_{\mathrm{m}}
\end{array}\right]
\end{aligned}
$$

and $\mathrm{C}(\mathrm{t})=\left[\begin{array}{cccccccc}-\mathrm{s} \beta_{\mathrm{t}} & \mathrm{c} \beta_{\mathrm{t}} & 0 & 0 & 0 & 0 & 0 & 0 \\ -\mathrm{s} \varepsilon_{\mathrm{m}} \mathrm{c} \beta_{\mathrm{t}} & -\mathrm{s} \varepsilon_{\mathrm{m}} \mathrm{s} \beta_{\mathrm{t}} & \mathrm{c} \varepsilon_{\mathrm{m}} & 0 & 0 & 0 & 0 & 0\end{array}\right]$

It is obvious that

$$
\begin{aligned}
& \mathrm{C}(\mathrm{t}) \mathrm{B}(\mathrm{x}, \mathrm{t})=0 \text {, for all } \mathrm{t} \\
& \dot{\mathrm{C}}(\mathrm{t}) \mathrm{B}(\mathrm{x}, \mathrm{t})=0 \text {, for all } \mathrm{t} \\
& \dot{\mathrm{C}}(\mathrm{t}) \mathrm{A}^{2}(\mathrm{x}, \mathrm{t})=0 \text {, for all } \mathrm{t} \\
& \mathrm{C}(\mathrm{t}) \mathrm{A}(\mathrm{x}, \mathrm{t}) \mathrm{B}(\mathrm{x}, \mathrm{t})=\mathrm{D}(\mathrm{t}) \mathrm{T}_{\mathrm{IM}}(\mathrm{t}) \text {, for all } \mathrm{t}
\end{aligned}
$$

Then obtaining the first and second derivative of e(t) using (17) results in

$$
\begin{aligned}
\dot{\mathrm{e}}(\mathrm{t}) & =\mathrm{C}(\mathrm{t}) \dot{\mathrm{X}}(\mathrm{t})+\dot{\mathrm{C}}(\mathrm{t}) \mathrm{X}(\mathrm{t})=\mathrm{C}(\mathrm{t})[\mathrm{A}(\mathrm{x}, \mathrm{t}) \mathrm{X}(\mathrm{t})+\mathrm{B}(\mathrm{x}, \mathrm{t}) \mathrm{u}(\mathrm{t})]+\dot{\mathrm{C}}(\mathrm{t}) \mathrm{X}(\mathrm{t}) \\
& =[\mathrm{C}(\mathrm{t}) \mathrm{A}(\mathrm{x}, \mathrm{t})+\dot{\mathrm{C}}(\mathrm{t})] \mathrm{X}(\mathrm{t}) \\
\ddot{\mathrm{e}}(\mathrm{t}) & =[\mathrm{C}(\mathrm{t}) \mathrm{A}(\mathrm{x}, \mathrm{t})+\dot{\mathrm{C}}(\mathrm{t})] \mathrm{A}(\mathrm{x}, \mathrm{t}) \mathrm{X}(\mathrm{t})+\mathrm{B}(\mathrm{x}, \mathrm{t}) \mathrm{u}(\mathrm{t})] \\
& +[\dot{\mathrm{C}}(\mathrm{t}) \mathrm{A}(\mathrm{x}, \mathrm{t})+\ddot{\mathrm{C}}(\mathrm{t})] \mathrm{X}(\mathrm{t}) \\
& =\left[\mathrm{C}(\mathrm{t}) \mathrm{A}^{2}(\mathrm{x}, \mathrm{t})+2 \dot{\mathrm{C}}(\mathrm{t}) \mathrm{A}(\mathrm{x}, \mathrm{t})+\ddot{\mathrm{C}}(\mathrm{t})\right] \mathrm{X}(\mathrm{t})+\mathrm{D}(\mathrm{t}) \mathrm{T}_{\mathrm{IM}}(\mathrm{t}) \mathrm{u}(\mathrm{t}) \\
& =[2 \dot{\mathrm{C}}(\mathrm{t}) \mathrm{A}(\mathrm{x}, \mathrm{t})+\ddot{\mathrm{C}}(\mathrm{t})] \mathrm{X}(\mathrm{t})+\mathrm{D}(\mathrm{t}) \mathrm{T}_{I M}(\mathrm{t}) \mathrm{u}(\mathrm{t})
\end{aligned}
$$

Since $s(x, t)=\left(\frac{d}{d t}+\lambda\right) e(t)=I_{2 \times 2} \dot{e}(t)+\left[\begin{array}{cc}\lambda_{1} & 0 \\ 0 & \lambda_{2}\end{array}\right] e(t)$ then

$$
\dot{\mathrm{s}}(\mathrm{x}, \mathrm{t})=\mathrm{I}_{2 \times 2} \ddot{\mathrm{e}}(\mathrm{t})+\left[\begin{array}{cc}
\lambda_{1} & 0 \\
0 & \lambda_{2}
\end{array}\right] \dot{\mathrm{e}}(\mathrm{t})
$$

Substituting (18) and (19) into (20) gives 


$$
\dot{\mathrm{s}}(\mathrm{x}, \mathrm{t})=\bar{\lambda}[\mathrm{C}(\mathrm{t}) \mathrm{A}(\mathrm{x}, \mathrm{t})+\dot{\mathrm{C}}(\mathrm{t})] \mathrm{X}(\mathrm{t})+[2 \dot{\mathrm{C}}(\mathrm{t}) \mathrm{A}(\mathrm{x}, \mathrm{t})+\ddot{\mathrm{C}}(\mathrm{t})] \mathrm{X}(\mathrm{t})+\mathrm{D}(\mathrm{t}) \mathrm{T}_{\mathrm{IM}}(\mathrm{t}) \mathrm{u}(\mathrm{t})
$$

By setting $\dot{\mathrm{s}}(\mathrm{x}, \mathrm{t})=0$, the equivalent control law, $\hat{\mathrm{u}}$, can be derived using (8) as

$$
\hat{u}(t)=-T_{I M}^{T}(t) D^{T}(t)[\bar{\lambda} C(t) A(x, t)+\bar{\lambda} \dot{C}(t)+2 \dot{C}(t) A(x, t)+\ddot{C}(t)] X(t)
$$

Thus, the control law that satisfies the sliding mode condition could be obtained as

$$
\overline{\mathrm{u}}(\mathrm{t})=\left[\begin{array}{lll}
0 & 1 & 0 \\
0 & 0 & 1
\end{array}\right] \hat{\mathrm{u}}(\mathrm{t})-\mathrm{T}_{\mathrm{IM}}^{\mathrm{T}}(\mathrm{t}) \mathrm{D}^{\mathrm{T}}(\mathrm{t}) \mathrm{K} \operatorname{sign}[\mathrm{s}(\mathrm{x}, \mathrm{t})]
$$

where $\operatorname{sign}[\mathrm{s}(\mathrm{x}, \mathrm{t})]=\left[\operatorname{sign}\left(\mathrm{s}_{1}\right), \operatorname{sign}\left(\mathrm{s}_{2}\right)\right]^{\mathrm{T}}, \mathrm{K}$ is $(2 \times 2)$ diagonal matrix with chosen positive elements $\mathrm{k}_{\mathrm{ii}}, \mathrm{i}=1,2$, and $\overline{\mathrm{u}}(\mathrm{t})=\left[\mathrm{a}_{\mathrm{yc}}, \mathrm{a}_{\mathrm{zc}}\right]^{\mathrm{T}}$.

It is obvious that the control law consists of a switching component superimposed on a continuous one named the equivalent control which is determined on the basis of the nominal model. The equivalent control is determined to cancel the known terms on the right hand side of (21). By substituting the control law of (23) to (21) after some simple manipulation, we can obtain $\dot{\mathrm{s}}(\mathrm{x}, \mathrm{t})$ as

$$
\dot{\mathrm{s}}(\mathrm{x}, \mathrm{t})=-\mathrm{K} \operatorname{sign}(\mathrm{s})
$$

To show stability in the sense on Lyapunov theory, define a Lyapunov function V

$$
\mathrm{V}=\frac{1}{2} \mathrm{~s}^{\mathrm{T}} \mathrm{s}
$$

Thus, substituting (24) into (25) results in

$$
\begin{aligned}
\dot{\mathrm{V}} & =\mathrm{s}^{\mathrm{T}} \dot{\mathrm{s}} \\
& =-\mathrm{s}^{\mathrm{T}} \mathrm{K} \operatorname{sign}(\mathrm{s})
\end{aligned}
$$

This means that $\dot{\mathrm{V}}<0$ for all positive values of the elements of the diagonal matrix $\mathrm{K}$.

$$
\text { i.e. } \mathrm{s}^{\mathrm{T}}(\mathrm{x}, \mathrm{t}) \dot{\mathrm{s}}(\mathrm{x}, \mathrm{t})<0 \quad \forall \mathrm{k}>0
$$

The condition in (27) satisfies

$$
\begin{array}{ll}
\dot{\mathrm{s}}(\mathrm{x}, \mathrm{t})<0 & \text { if } \mathrm{s}(\mathrm{x}, \mathrm{t})>0 \\
\dot{\mathrm{s}}(\mathrm{x}, \mathrm{t})>0 & \text { if } \mathrm{s}(\mathrm{x}, \mathrm{t})<0
\end{array}
$$

In other words, the chosen control law satisfies the sliding mode condition (28) with satisfactory condition that the trajectories remain on the sliding surfaces and eventually tracking errors would be driven to zero.

\section{Fuzzy Sliding Mode Command Guidance}

One of the assumptions in the design of the sliding mode control command guidance law has been that the missile demanded acceleration can be instantaneously switched from one value to another. However, toggling of the control at a very fast rate will result in the problem commonly called chattering.

An approach to enhance robustness and disturbance rejection capabilities of SMC is the combination with FLC. Although FLC is similar to SMC, the combination of what is called FSMC is a promising approach. One important feature could result from FSMC is the ability 
of FLC to eliminate chattering, which is an important problem commonly recorded as a drawback of sliding mode controller.

Instead of the constant gain matrix $\mathrm{K}$ of the sign function in the sliding surface in (23), an adaptive gain matrix $\mathrm{K}$ based on FLC is proposed. Because choosing values of constant gain matrix $\mathrm{K}$ to ensure stability can lead to a very high gain controller the adaptive gain matrix $\mathrm{K}$ is used to cope with this practical implementation and high cost problems.

Rewriting the second term on the right hand side of control law (24) as

$$
u_{s}=-T_{I M}^{T}(t) D^{T}(t) K \operatorname{sign}[s(x, t)]
$$

This part can be interpreted as a nonlinear feedback with its sign toggling between plus and minus based on which side of the sliding surface the system is located. Thus,

$$
u_{s f}=-T_{I M}^{T}(t) D^{T}(t) K_{f}(s, \dot{s}) \operatorname{sign}[s(x, t)]
$$

where $\mathrm{K}_{\mathrm{f}}(\mathrm{s}, \dot{\mathrm{s}})$ is the output of the FLC. Sometimes the guidance law is deactivated shortly before intercept to prevent sending erroneous or unachievable manoeuvre commands to the autopilot. The use of proximity fuses and the large size of the target relative to the missile, mean that final miss distance does not need to be zero, so perfect tracking of commands in the end-game is desirable but not required. In another words, a degradation of the performance could be acceptable and the chattering effect may be moderated by the introduction of a boundary layer with thickness $\phi$ instead of the sign function in (30). Thus,

$\mathrm{u}_{\mathrm{sf}}=-\mathrm{T}_{\mathrm{IM}}^{\mathrm{T}}(\mathrm{t}) \mathrm{D}^{\mathrm{T}}(\mathrm{t}) \mathrm{K}_{\mathrm{f}}(\mathrm{s}, \dot{\mathrm{s}}) \operatorname{sat}[\mathrm{s}(\mathrm{x}, \mathrm{t}) / \phi]$

where $\operatorname{sat}[\mathrm{s}(\mathrm{x}, \mathrm{t}) / \phi]= \begin{cases}\mathrm{s} / \phi, & \text { if }|\mathrm{s} / \phi| \leq 1 \\ \operatorname{sign}(\mathrm{s} / \phi), & \text { otherwise }\end{cases}$

To design the FLC to generate $\mathrm{K}_{\mathrm{f}}(\mathrm{s}, \dot{\mathrm{s}}) \operatorname{sat}[\mathrm{s}(\mathrm{x}, \mathrm{t}) / \phi]$ in (31) a two parallel structure FLC is proposed as shown in Fig. 2. In general a FLC contains four main components; fuzzification, rule-base, inference mechanism, and defuzifiaction. The fuzzification interface simply modifies the inputs so that they can be interpreted and compared to the rules in the rule base. The rule base holds the knowledge in the form of a set of rules of how best to control the system. The inference mechanism or the decision making logic evaluates which control rules are relevant at the current time and then decides what is the input to the plant should be. The defuzzification interface converts the conclusions reached by the inference mechanism into the inputs to the plant to be controlled.

A fuzzy adaptive gain $\mathrm{k}_{\mathrm{ii}}$ for each plane of guidance (pitch and yaw), as an output of FLC1 in the suggested FSMC via defuzzification, will have two inputs: the sliding signals s(e,e) and the rate of change of the sliding signals $\dot{\mathrm{s}}(\dot{\mathrm{e}}, \ddot{\mathrm{e}})$. Since the saturating control function is desired, the membership functions for all the inputs of the FLC are chosen to be the same. Based on the similarity between the FLC and SMC and the chosen membership functions, a sample fuzzy control rule is presented as 
If $\mathrm{s}$ is positive big AND ds/dt is positive big THEN $\mathrm{k}_{\mathrm{f}}$ is negative big

In this paper, the triangular membership function, the minimum-maximum reasoning method, and the center-of-gravity (CoG) defuzzification method are used. The crisp output is obtained by calculating the $\mathrm{CoG}$ of the output fuzzy set. For continuous membership function, the $\mathrm{CoG}$ defuzzification method is defined as

$$
\text { C.O.G. }=\frac{\int_{A}^{B} \mu_{F}(Z) \cdot Z \partial Z}{\int_{A}^{B} \mu_{F}(Z) \partial Z}
$$

where $\mu_{\mathrm{F}}(\mathrm{Z})$ is the output membership function and $\mathrm{A}$ and $\mathrm{B}$ are the intervals of the output $\mathrm{Z}$ in which the fuzzy set has a non-zero membership value. This method of defuzzification produces smooth output. This is the most widely adopted defuzzification strategy especially for continuous systems where the fuzzy sets heavily overlap.

The role of FLC2 in the suggested FSMC is to replace a fixed boundary layer thickness of a saturation function with a time-varying one based on a specified rule base. The rule base is obtained by a designed rule as follows:

$\mathrm{R \# 1}$ : IF $\mathrm{s}$ is big THEN $\phi$ is narrow.

$\mathrm{R} \# 2$ : IF $\mathrm{s}$ is small THEN $\phi$ is wide.

$\mathrm{R} 1$ is to make boundary layer thickness narrow to achieve the fast convergence to sliding surface. However, R2 is to make boundary layer thickness wide in order to alleviate chattering.

\section{Simulation Results}

Numerical simulations are performed to investigate the performance of the proposed guidance law in the presence of highly manoeuvring targets. The missile model in this paper is a medium range surface-to-air missile. The missile mass depends on the fuel rate of consumption. In order to simplify the computation, we assume that the time dependence of the missile mass is a linear one. This assumption enables us to calculate the value of this variable at any instant if we know the corresponding values at ignition and burnout of the missile motor. If we denote by $t_{0}$ the initial time of flight, $t_{1}$ the time when the boaster motor burnout, and $t_{2}$ the time when the sustainer motor burnout, then we can calculate the value of this variable at any time provided that the values of $t_{0}, t_{1}$, and $t_{2}$ are known. The computer program involves the following equations

$$
\begin{array}{ll}
\operatorname{mass}(\mathrm{t})=\operatorname{mass}\left(\mathrm{t}_{\mathrm{O}}\right)-\left\{\operatorname{mass}\left(\mathrm{t}_{\mathrm{o}}\right)-\operatorname{mass}\left(\mathrm{t}_{1}\right)\right\}\left(\mathrm{t}-\mathrm{t}_{\mathrm{o}}\right) /\left(\mathrm{t}_{1}-\mathrm{t}_{\mathrm{o}}\right), & \left\{\mathrm{t}<\mathrm{t}_{1}\right\} \\
\operatorname{mass}(\mathrm{t})=\operatorname{mass}\left(\mathrm{t}_{1}\right)-\left(\operatorname{mass}\left(\mathrm{t}_{1}\right)-\operatorname{mass}\left(\mathrm{t}_{2}\right)\right)\left(\mathrm{t}-\mathrm{t}_{1}\right) /\left(\mathrm{t}_{2}-\mathrm{t}_{1}\right), & \left\{\mathrm{t}_{1}<\mathrm{t}<\mathrm{t}_{2}\right\}
\end{array}
$$

The thrust vector is considered to be along the missile longitudinal axis and it is assumed to be constant during the booster and sustainer stages. It is noted that the sustainer thrust value is 
different from that of the booster one as shown in Fig. 3. The drag force, D, has been calculated as

$$
\mathrm{D}=\mathrm{C}_{\mathrm{x}} \mathrm{S}\left(1 / 2 \rho \mathrm{V}_{\mathrm{m}}^{2}\right)
$$

where $C_{x}$ is the aerodynamic drag coefficient and $S$ is the reference cross-sectional area. The air density, $\rho$, is measured in $\mathrm{Kg} / \mathrm{m}^{3}$ and is approximated as [4]

$\rho=1.2255\left(1-0.000022557 \mathrm{z}_{\mathrm{m}}\right)^{4.2561}$

Before proceeding with the simulation studies, the target motion model is assumed to produce no axial acceleration or roll motion. Then, the simplified dynamics of target motion can be presented in the inertial frame as follow [7]

$$
\begin{aligned}
& \ddot{x}_{t}=-a_{t y} s \psi_{t}-a_{t z} s \theta_{t} c \psi_{t} \\
& \ddot{y}_{t}=a_{t y} c \psi_{t}-a_{t z} s \theta_{t} s \psi_{t} \\
& \ddot{z}_{t}=a_{t z} c \theta_{t}-g \\
& \dot{\psi}_{t}=a_{t y} /\left(v_{t} c \theta_{t}\right) \\
& \dot{\theta}_{t}=\left(a_{t z}-g c \theta_{t}\right) / v_{t}
\end{aligned}
$$

where $\theta_{\mathrm{t}}$ and $\psi_{\mathrm{t}}$ are the target pitch and yaw angles respectively, and $\mathrm{x}_{\mathrm{t}}, \mathrm{y}_{\mathrm{t}}$, and $\mathrm{z}_{\mathrm{t}}$ are the target position in the inertial frame respectively, however, $a_{t z}$ and $a_{t y}$, represent the pitch and yaw target manoeuvres respectively. The notation $s \psi_{\mathrm{t}}, \mathrm{c} \psi_{\mathrm{t}}$, etc. are the $\sin \psi_{\mathrm{t}}$ and $\cos \psi_{\mathrm{t}}$, etc.

The target velocity $v_{t}$ is given by

$$
\left.\mathrm{v}_{\mathrm{t}}=\stackrel{\Delta}{=} \dot{\mathrm{x}}_{\mathrm{t}}^{2}+\dot{\mathrm{y}}_{\mathrm{t}}^{2}+\dot{\mathrm{z}}_{\mathrm{t}}^{2}\right)^{1 / 2}
$$

Specific simulation studies are presented for two engagement scenarios. In engagement scenario 1 , initial receding target velocity $(\mathrm{m} / \mathrm{sec})$ is [250 50 50], initial target position $(\mathrm{m})$ is [5000 $5000-5000]$, and evasive target acceleration $\left(\mathrm{m} / \mathrm{sec}^{2}\right)$ as can be seen from Fig. 4, we assume that the target manoeuvres with $\mathrm{a}_{\mathrm{ty}}= \pm 5 \mathrm{~g}$ and $\mathrm{a}_{\mathrm{tz}}= \pm 5 \mathrm{~g}$ until interception. In engagement scenario 2, initial approaching target velocity $(\mathrm{m} / \mathrm{sec})$ is [350 50 50], initial target position (m) is [15000 $3000-2000]$, and evasive target acceleration $\left(\mathrm{m} / \mathrm{sec}^{2}\right)$ as can be seen from Fig. 3, we assume that the target manoeuvres with $\mathrm{a}_{\mathrm{ty}}= \pm 3 \mathrm{~g}$ and $\mathrm{a}_{\mathrm{tz}}= \pm 3 \mathrm{~g}$ until interception.

In the presented simulation studies, the plant introduced is controlled by the proposed control scheme. The aim of the FSMC is to produce guidance command signals to move the missile as closely as possible on the line joining the tracker and the target. In another words, the generated command signals will result in the observation of a sliding motion in the phase plane.

In practical implementations there are some fundamental features that limit the accuracy of the LOS guidance system. The firstly difficulty to be alleviated is the randomly high 
manoeuvring target and the effect of autopilot dynamics. The second difficulty is the nonzero initial conditions, which are simulated by the initial heading error angle between the missile and the target and/or missile command guidance generation delay until the missile reaches the nominal speed. The third difficulty that is very likely to be encountered is the existence of the measurement noise. To study the effects of this measurement noise, a Gaussian distributed random noise with zero means has been considered. The magnitude of the noise is chosen to be within $\pm 0.3 \mathrm{deg}$ (or the equivalent in metter).

To compare the control performance of the FSMC with the conventional SMC, the sliding mode control law designed by Slotine and Li [17] as in Eq. (14) is adopted in this comparison process. The simulation is carried out using "BORLAND-C" package. The simulation results of the sliding mode control due to missile-target engagement scenario 1 are shown in Fig. 5(b,d,f). However favourable tracking responses in the pitch and yaw plan can be achieved by the sliding mode control, the chattering control efforts caused by the toggling process results in performance degradation and may lead to instability problem and/or excite one of the missile unmodeled dynamics (body bending modes).

The simulation results of the FSMC due to missile-target engagement scenario 1 are shown in Figs. 5(a,c,e). The proposed FSMC command guidance laws is able to overcome the initial heading error angle between the missile and the target in addition to the missile command guidance generation time delay $(2 \mathrm{sec})$ until the missile reaches the nominal speed. It is obvious from the phase plane trajectory that the error goes to the sliding regime with the reaching law until interception. In another words, although there is nonzero initial conditions accurate tracking performance is obtained. Also, chattering phenomena has been alleviated as shown in Figs. 5(d,f) the phase plan trajectory and the associated control efforts. Moreover, the robust control performance of the FSMC in the existence of the missile and target parameter variations, external noise, and autopilot dynamics, are obvious as shown in Table 1. Twenty-five runs with independent measurement noise resulted in satisfactory root mean square miss distance. Furthermore, the missile-target engagement scenarios presented in figures $(6,8)$ demonstrate the effectiveness of the proposed missile guidance law against different engagement scenarios. The associated control signals are shown in Figs. $(7,9)$ in which the smoothness of the signal is a very important characteristic.

\section{Conclusion}

A direct approach to design a more robust stable command guidance law is proposed using sliding mode control. The guidance command is derived based on trajectory tracking error problem. A FSMC has been successfully developed in this research for the missile-target tracking error problem. The chattering problem may result in performance degradation and/or excite the missile body bending dynamics (elastic modes). Moreover, the proposed FSMC combines the advantages of SMC with robust and inherent stability characteristics and FLC more robust ability and reduced rule base. Furthermore, the simulation results show the effectiveness of the proposed missile guidance law against different engagement scenarios. 


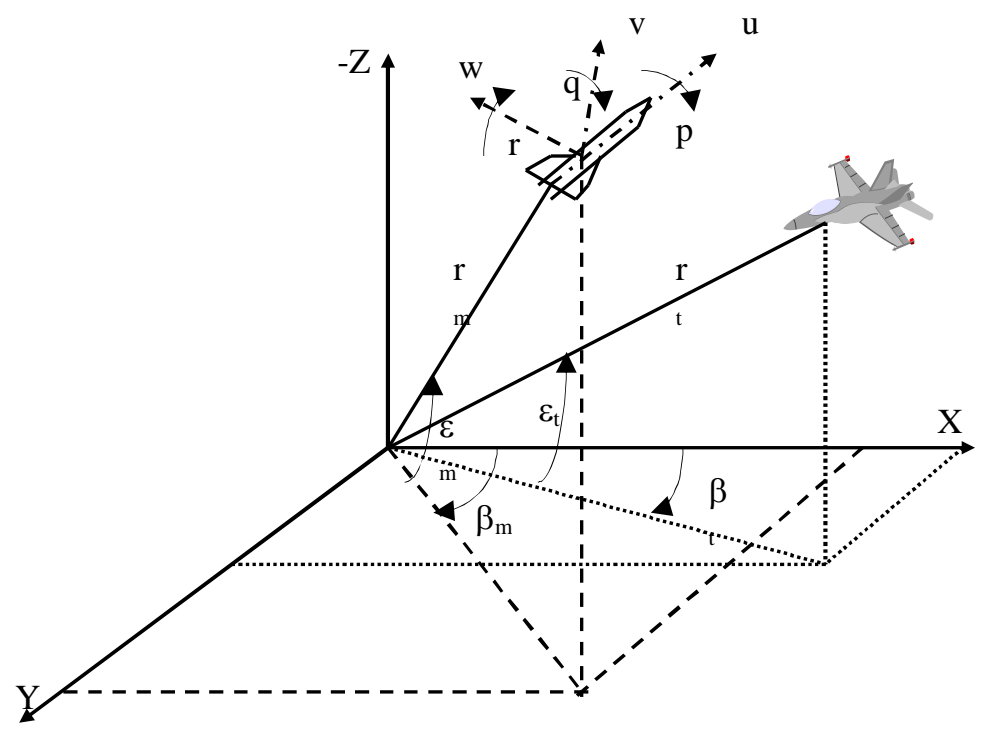

Fig. 1 Missile-target geometry.

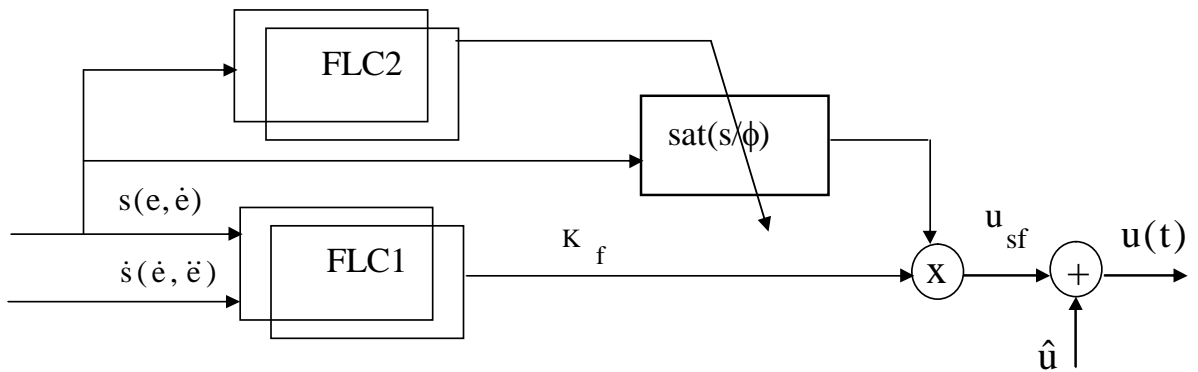

Fig. 2 Fuzzy sliding mode controller with time-varying boundary layer.

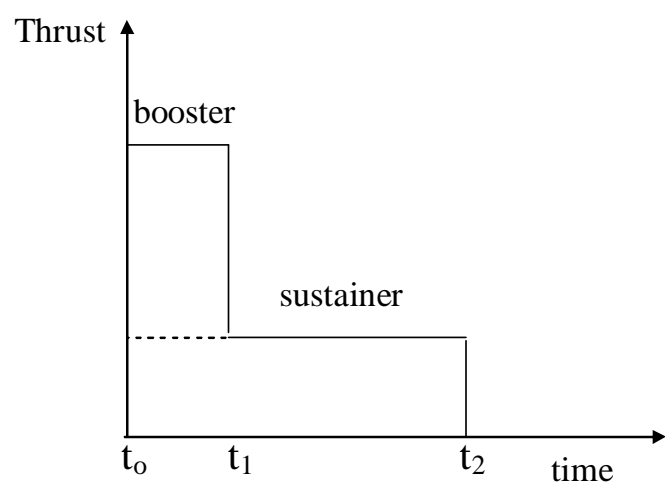

Fig. 3 Missile thrust profile
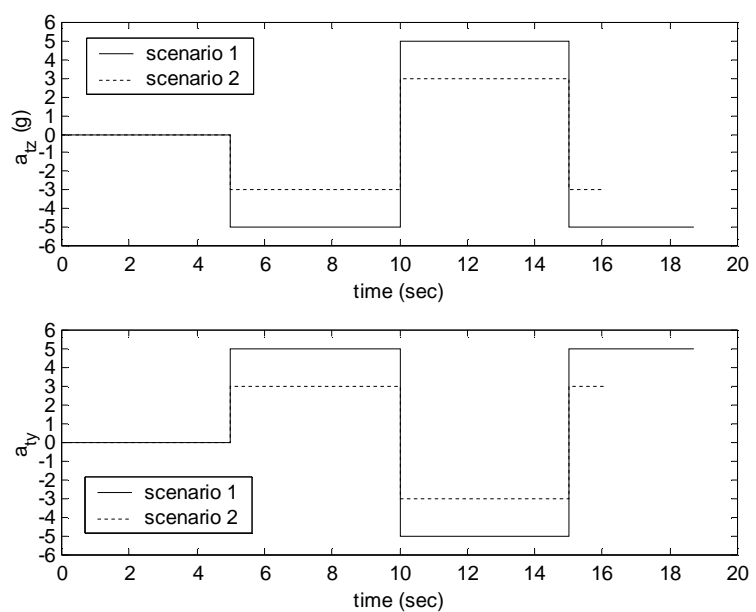

Fig. 4 Target acceleration time history $\left(\mathrm{g}=9.81 \mathrm{~m} / \mathrm{sec}^{2}\right)$ 

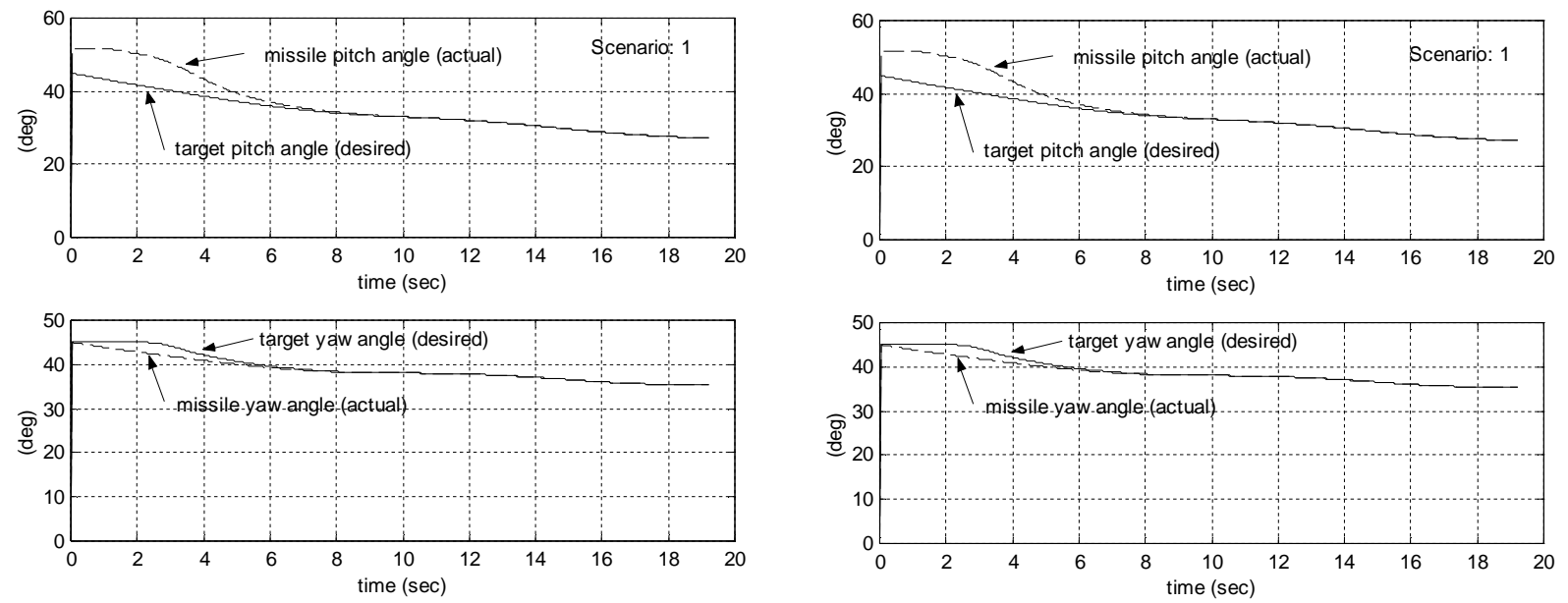

(a)

(b)

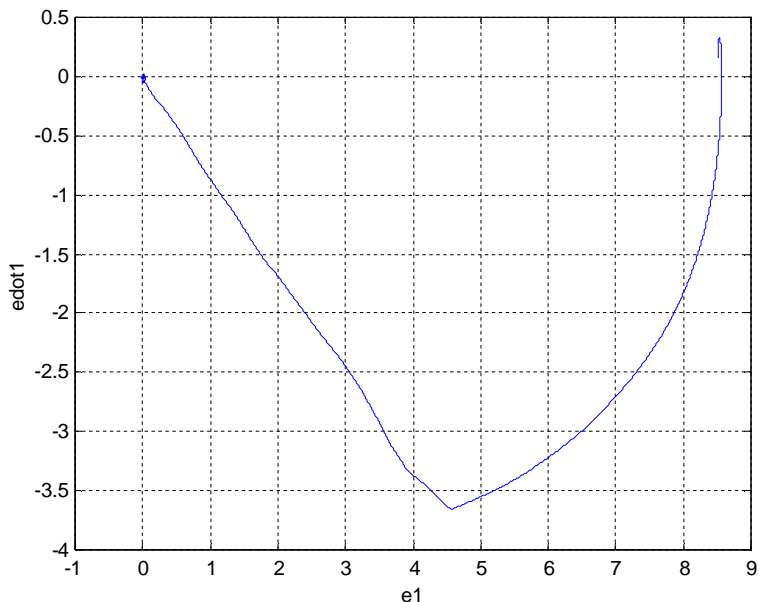

(c)
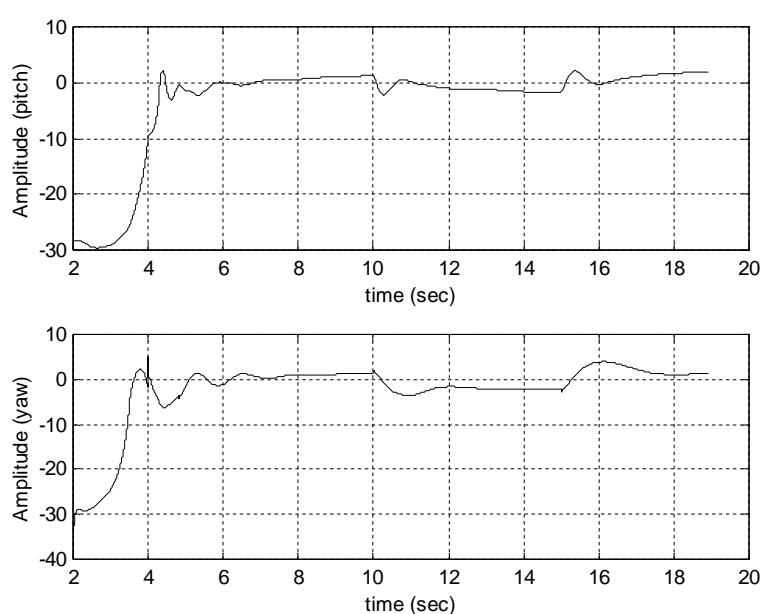

(e)

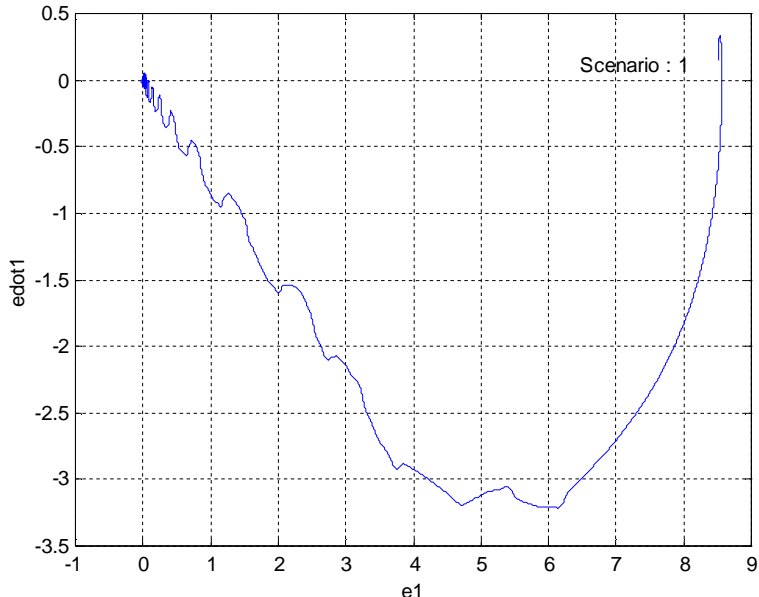

(d)
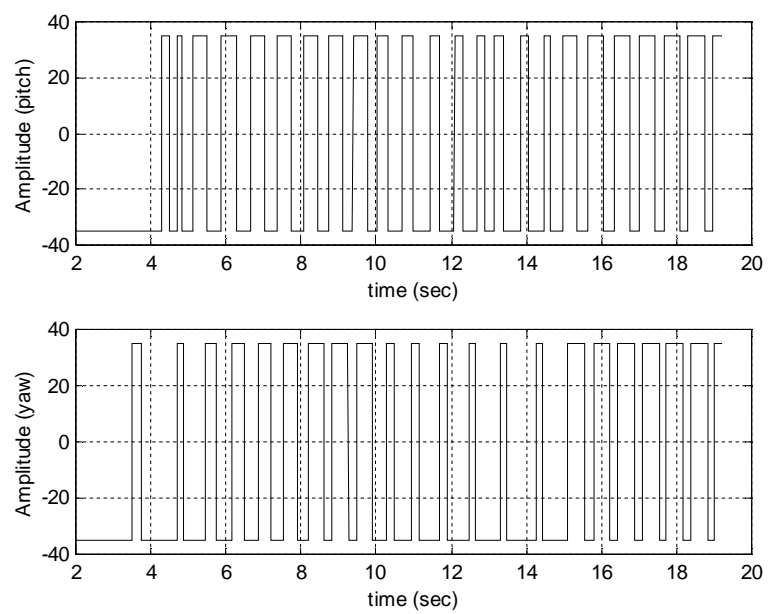

(f)

Fig. 5 Simulation results of the conventional SMC versus the proposed FSMC.

(a), (b) Tracking response at scenario 1: Desired target angle (pitch/yaw) Actual missile angle (pitch/yaw);

(c), (d) Phase plane trajectory;

(e), (f) Control effort (pitch/yaw m/ $/ \mathrm{sec}^{2}$ ) 


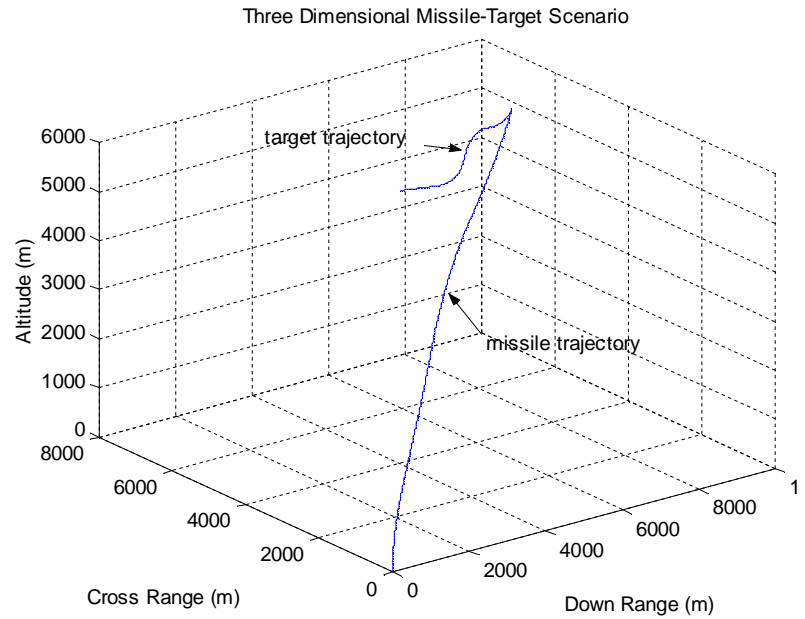

Fig. 6 Missile-target engagement. scenario 1

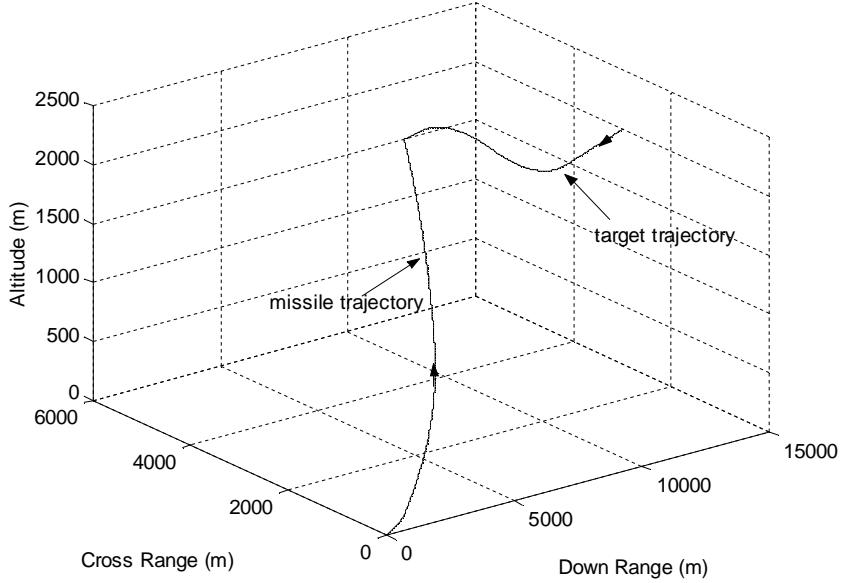

Fig. 8 Missile-target engagement. scenario 2
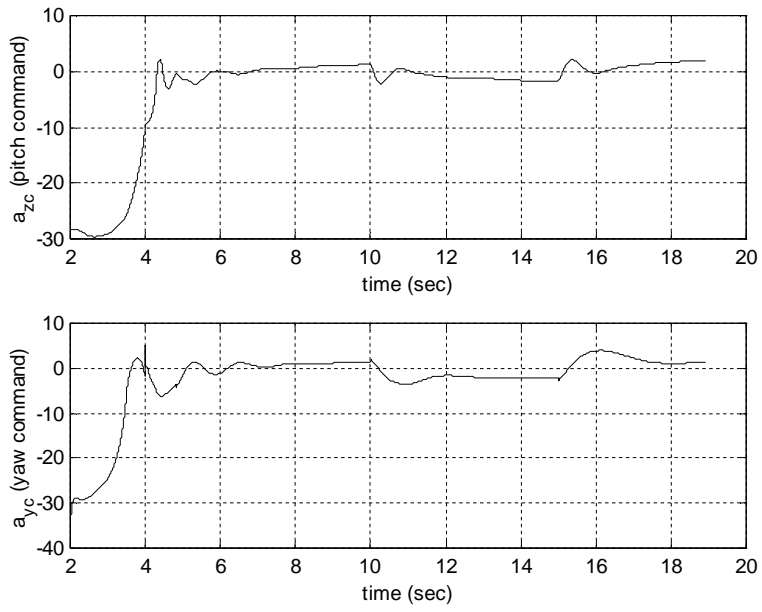

Fig. 7 Command Control signal scenario 1
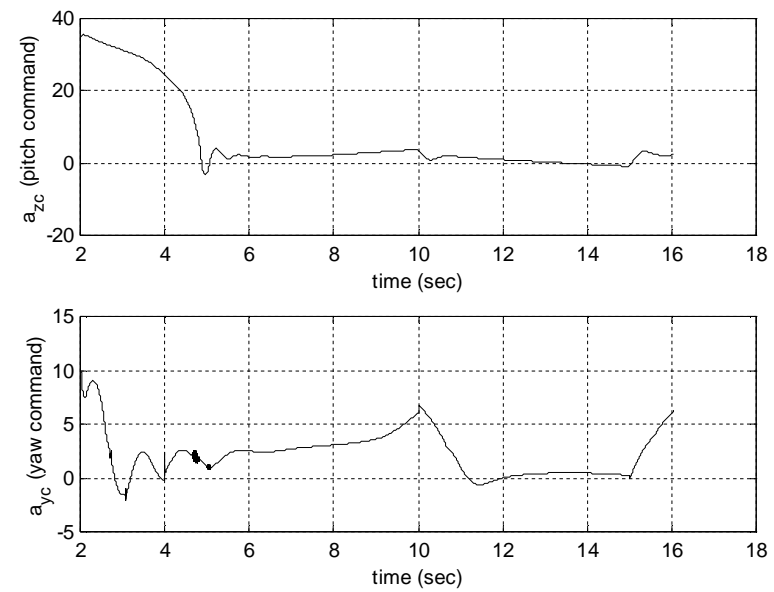

Fig. 9 Command Control signal.

Scenario 2

Table 1 Effect of measurement noise and autopilot dynamics on Miss Distance (meter)

\begin{tabular}{|c|c|c|c|}
\cline { 3 - 4 } \multicolumn{2}{c|}{} & Scenario 1 & Scenario 2 \\
\hline zero autopilot & without noise & 0.872 & 1.532 \\
\cline { 2 - 4 } dynamics & With noise & 1.236 & 1.825 \\
\hline with autopilot & without noise & 2.369 & 3.094 \\
\cline { 2 - 4 } dynamics & With noise & 5.057 & 5.450 \\
\hline
\end{tabular}




\section{References}

[1] Locke, A., "Principles of Guided Missile Design”, D. Van Nostrand Co., Princeton, NJ, U.S.A., 1955.

[2] Garnell, P., and East, D. J., "Guided Weapon Control Systems", $2^{\text {nd }}$ Ed., Pergaman press, New York, 1980.

[3] Lin, C-F, "Modern Navigation, Guidance, and Control Processing", Prentice Hall, Englewood cliffs, NJ, USA, 1991.

[4] Zarchan, P., "Tactical and Strategic Missile Guidance", $2^{\text {nd }}$ ed., Vol. 157, Progress in Astronautics and Aeronautics, AIAA, Washington, DC, 1994.

[5] Macfadzean, R. H. M., "Surface Based Air Defence System Analysis", Artech House, Norwood, MA, 1992.

[6] Shneydor, N. A., "Missile Guidance and Pursuit: Kinematics, Dynamics, and Control", Horwood Publishing, Chichester, England, UK, 1998.

[7] Ha, I. J., and Chong, S., "Design of a CLOS Guidance Law via Feedback Lineraization", IEEE Transactions on Aerospace and Electronic Systems, Vol. 28, No. 1, 1992, pp. 51-63.

[8] J. Huang and C.-F., Lin, "A Modified CLOS Guidance Law Via Right Inversion", IEEE Transactions of Aerospace and Electronic Systems, Vol. 31, No. 1, 1995.

[9] G. T. Lee and J. G. Lee, "Improved Command to Line-of-Sight for Homing Guidance", IEEE Transactions of Aerospace and Electronic Systems, Vol. 31, No. 1, 1995.

[10] S. H., Jalali-Nain and V. Esfahanian, " Closed Form Solution of Line-of-Sight Trajectory for Nonmanoeuvring Target", AIAA Journal of Guidance, Control, and Dynamics, Vol. 23, No. 2, pp. 365-366, 2000.

[11] R. M. Shoucri, " Closed Form Solution of Line-of-Sight Trajectory for Manoeuvring Target", AIAA Journal of Guidance, Control, and Dynamics, Vol. 24, No. 2, pp. 408409, 2001.

[12] S. H., Jalali-Nain, "Analytical Study of A Modified LOS Guidance", AIAA Guidance, Navigation, and Control Conference, Montreal, Canada, 2001, A01-37024.

[13] Brierly, S. D., and Longchamp, R., "Application of Sliding-Mode Control to Air-Air Interception Problem", IEEE Transactions of Aerospace and Electronic Systems, Vol. 26, No. 2, 1990.

[14] Zho, D., et al, "Adaptive Sliding Mode Control Guidance of a Homing Missile", Journal of Guidance, Control, and Dynamics, Vol. 22, No. 4, 1999, pp. 589-594.

[15] Babu, K. R., Sarma, I. G., and Swamy, K. N., "Switched Bias Proportional navigation for Homing Guidance Against Highly Manoeuvring target", Journal of Guidance, Control, and Dynamics, Vol. 17, No. 6, 1994, pp. 1357-1363.

[16] I. Shkolnikov, Y. Shtessel, and D. Lianos. "Integrated Guidance-Control System of a Homing Interceptor: Sliding Mode Approach", AIAA GN\&C Conference, 2001.

[17] K. M. Passsino and S. Yurkovich, "Fuzzy Control", Addison Wesly Longman, Inc., 1998.

[18] J. J. E. Slotine and W. Li, “Applied Nonlinear Control”, Prentice-Hall, Upper Saddle River, NJ, 1991.

[19] R. Palm, "Robust Control by Fuzzy Sliding Mode", Automatica, Vol. 30, No. 9. pp. 1429-1437, 1994. 